\title{
Successful Management of Respiratory Syncytial Virus Outbreak in a Hematology and Bone Marrow Transplant Unit
}

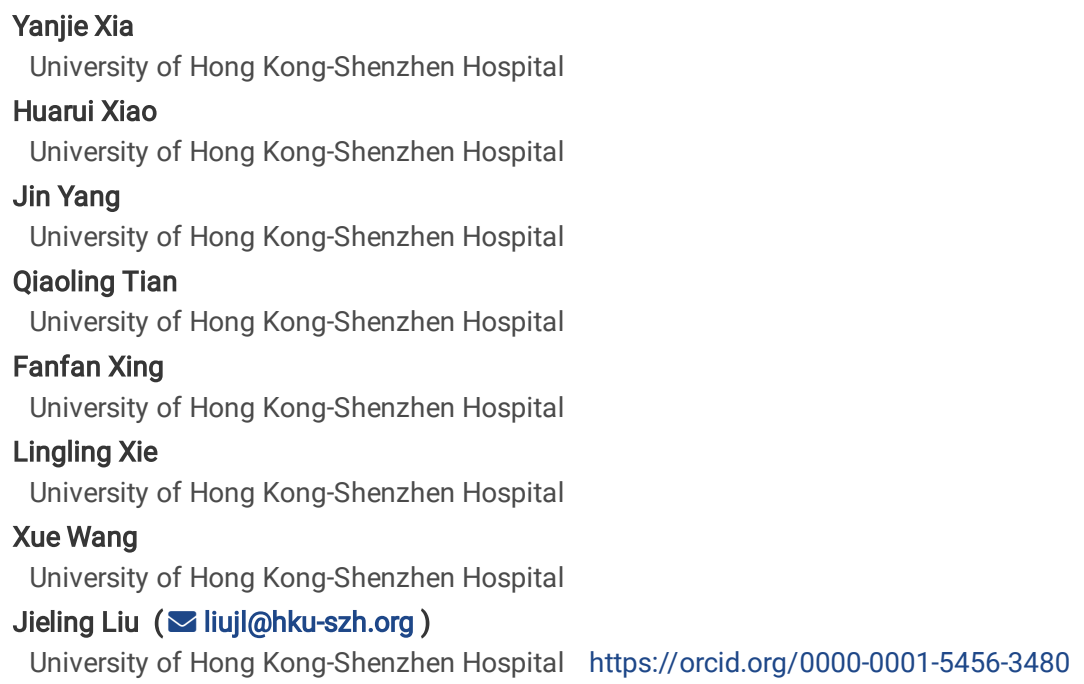




\section{Abstract}

Background: Respiratory Syncytial Virus (RSV)is recognized as one of the most common causes of acute respiratory infections in adults which is associated with significant morbidity and mortality in the elderly and immunocompromised adults. Moreover RSV can spread rapidly through close contact through respiratory droplets leading to clusters of cases or outbreaks in health care facilities. Herein we demonstrate the successful control and the risk factors of the RSV outbreak involving 39 patients in a Hematology and Bone Marrow Transplant(BMT) Unit.

Methods: We performed an epidemiological investigation,analyzed the risk factors and implemented the infection control measures for this nosocomial RSV outbreak in the Hematology and BMT Unit. Furthermore we implemented the RSV screening for all the inpatients and medical staff of Hematology and BMT Unit and the infection control bundles to stop the outbreak.

Results: 24 patients were tested positive for RSV, 2 of which were confirmed to be hospital acquired respiratory infection according to Chinese hospital infection diagnostic criteria,the other cases were hospital acquired. Our multimodal infection control bundle was able to rapidly control this outbreak,newly diagnosed patients with RSV infection were distributed in the first three weeks of this outbreak.All cases were discharged after recovery or remission.

Conclusion: The successful infection control management of RSV outbreak should include interruption of all potential transmission routes.In Hematology and BMT Unit, restriction of social activities is useful to stop RSV transmission despite some temporal negative impact on the emotional needs of the patients.Universal RSV screening and vigorous enforcement of infection control measures was effective in the containment of this outbreak.

\section{Background}

Human respiratory syncytial virus(RSV) belongs to the recently defined Orthopneumovirus of the family Pneumoviridae,which is a single stranded RNA-virus. It can cause seasonal respiratory tract infection(RTI) in children and adults ${ }^{[1-2]}$.Though RSV is usually a self-limiting disease,causing only mild symptoms of RTI or no symptoms at all,it may also be associated with severe lower respiratory tract disease in elderly or immunocompromised individuals ${ }^{[3-4]}$. The incubation period ranges from 2 to 8 days. Investigations showed that the human to human transmission takes place via respiratory droplets as well as direct and indirect contact. Patients with hematologic-related disorders are at high risk for RSV infection,especially in the context of hematopoietic stem cell transplantation (HSCT) ${ }^{[5-6]}$.

RSV,as well as RTI caused by influenza viruses,is usually community-acquired. Nevertheless, hospital acquisition is possible as RSV infected patients,visitors,companions,staff or their touched and therefore contaminated surfaces of the environment may serve as portals of transmission ${ }^{[7-8]}$.

RSV outbreak in inpatient hematology and oncology units have been described ${ }^{[8-9]}$.A good understanding of the transmission routes of RSV infection can help us implement measures for prevention and control.Treatment options for patients with hematopoietic stem cell transplant and severe blood disorders,who are severely infected by RSV include ribavirin and immunoglobulin ${ }^{[10-11]}$. However data about ribavirin is few, a pooled analysis suggests some effect ${ }^{[12]}$.

Here we present an outbreak of RSV infection in our adult hematology and BMT unit from June 30th to August 10th in 2020.We presented the analysis of this event which involved 39 patients, and defined the strategies for the successful management of RSV infections in immunocompromised patients.

\section{Methods}

\section{Study site}

The University of Hong Kong-Shenzhen Hospital(HKU-SZH) is a 3A general teaching hospital, the affiliated hospital of Hongkong University .The Department of Haematology consists of two inpatient wards,the general haematology ward and the haemopoietic stem cell transplant (BMT) Unit.The general haematology ward for non-cancer haematology patients and for chemotherapy patients consisted of 2 singles, 3 two-beds,and 12 three-bed rooms, and thus a total of 44 beds in 17 rooms. The BMT unit for autologous and allogeneic transplant has 7 single rooms, which are in the clean zone and equipped with highefficiency particulate air filtration. Patients in BMT rooms are strictly restricted to their rooms, whereas patients in the general hematology ward may gather to chat,visit each other,and even have meals together which are against the ward policies.

In 2019,a total of 45 cases were treated by autologous (22 cases) and allogeneic ( 23 cases) SCTs.

\section{Nosocomial RSV infection cases}

According to the Chinese hospital infection diagnostic criteria,nosocomial RSV infection cases are defined as hospital-acquired infections if they occur after 48 hours after admission after excluding the existence of upper respiratory tract infections or lower respiratory tract infections at the time of admission. The diagnosis of nosocomial acquired RSV depends on the clinical and microbiologic diagnostic criteria. The clinical criteria are divided into upper respiratory tract infection and lower respiratory tract infection. Having fever and upper respiratory tract symptoms such as nasal obstruction, rhinorrhea, sore throat is defined as upper respiratory tract infection disease(URTID). The presence of symptoms such as cough, along with one of three findings: fever, leukocytosis,neutrophilia, and new infiltrates in the lung may indicate lower respiratory tract infection disease(LRTID).

\section{Description of the RSV outbreak}

On June 30th,2020,three patients with respiratory symptoms in the haematology department required clinical consultation by our clinic microbiologist,all were tested positive for RSV.The hospital Infection Control Team(ICT) was alerted to investigate these cases who probably had hospital-acquired RSV infection. The 
clustering of these cases in the Hematology Department led to the activation of the hospital outbreak response plan with the formation of an investigation team including members of the Hematology Department囚Respiratory Department,Central Nursing Department and the head of Internal Medicine Department. A combined nasal and throat swab was taken for standard purpose, but nasopharyngeal or throat swabs may be taken due to medical reasons or patient refusal.Samples taken for diagnostic purpose were processed in Microbiology Lab using direct fluorescent antibody(DFA) staining or Gene X-pert RSV/Flu detection.

On July 1st,ICT took these samples from 51 medical staffs and 39 patients of Hematology Department. Laboratory testing showed 12 RSV-positive patients. On July 2nd, in view of the possibility of prolonged RSV shedding in immunosuppressed hosts, ICT decided to to re-sample for all patients once weekly.From June 30th to August 10th,ICT sampled 13 times for 39 patients and 52 medical staff. A total of 129 samples from patients,62 environmental samples from high frequency contact(HFC) surfaces and 52 samples from medical staffs.

\section{Ethical approval}

We obtained ethical approval for this study from the ethics committee of the HKU-SZH.

\section{Results}

\section{Outbreak and RSV monitoring}

The outbreak occurred in the Hematology and BMT unit for adults. The two wards were on the same floor. Some patients were first admitted to Hematology and then transferred to BMT unit if HSCT is indicated,and finally returned to Hematology after HSCT.Autologous and allogeneic HSCT are performed in BMT unit with 7 single rooms. The department is serviced by designated health care workers and cleaning staffs.

On June 30th,2020,3 patients(case14,15,23) were tested positive for RSV in nasopharyngeal samples. Characteristics of Patients with RSV infection are shown in Table 1. 2 patients fulfilled criteria for nosocomial acquired infection,as they had no underlying respiratory infection on admission. The remaining 22 patients were nosocomial acquired or RSV carriers because they were asymptomatic or already had respiratory symptoms or illness at the time of admission. The outbreak timeline with the diagnostic results can be seen in Fig1.Newly diagnosed patients with RSV were concentrated in first three weeks of the outbreak duration,and thereafter were repeatedly detected from the previous patients,seen in Fig 2.

9 patients received Ribavirin/immunoglobulin therapy(case4,5,6,8,14,15,19,20,23),other patients received antibiotic or other supportive treatment.No RSVrelated mortality was observed,all patients with RSV infection finally recovered or remission.

Viral persistence(viral shedding) is the time period from the first positive test to sustained negativity. Because patients cannot be monitored for RSV after discharge,only some patients can be monitored for persistent RSV shedding. The duration of viral shedding varied from at least 3 days(case 17,21$)$ to at least 34 days(case 14), shown in Table 1.

Meanwhile, ICT sampled 4 times from the environment of both wards, including HFC surfaces of patients with RSV infection,air and utensils for RSV. A total of 62 specimens were taken.Laboratory results showed that only 1 sample,the ring bell from patient(case17) were positive for RSV.See Fig 3 for details.

ICT also sampled respiratory specimens for all medical staff. All 52 specimens were negative.

\section{The outbreak control measures}

An outbreak contingency plan was developed after the detection of 3 RSV infected patients on June 30th,2020.During the outbreak period,daily or every 2 day meeting were held with stakeholders from relevant departments including Hematology,BMT Unit,ICT,the Microbiologists, Central Nursing Department,ICU,Respiratory, and Logistic Department. In addition to routine infection control measures,such as contact and droplet precautions for patients with either confirmed or suspected RSV infection who were already in the wards before the outbreak enhanced interventions were implemented. Strengthening the usual restrictions on access to the ward for visitors, accompanies and non-essential staff,with prohibition of visitors with fever and respiratory symptoms. All newly admitted patients were screened for RSV using DFA or Gene X-pert Flu/RSV detection.Once weekly RSV screening for all patients in the hematology and BMT Unit were performed till the end of this outbreak.Patients were instructed to wear masks,forbidden to visit each other or eat together in different rooms as usual.The patients with confirmed RSV infection were isolated in single rooms or placed in the shared rooms if no single rooms were available. Health care workers(HCW) used personnel protective equipment such as surgical mask or N95 mask,water-resistance gown,and gloves according to the operational risks in patient room. Once fever or respiratory symptoms appear, HCW who works in front-line should suspend work immediately until recovered.

ICT conducted adhoc training and supervision to improve compliance to the isolation procedure and hand hygiene. Environmental cleaning and disinfection of the wards, especially HFC surfaces were strengthened.

In view of the above strict measures, newly acquired RSV patients were controlled in the first three weeks of the duration,so we may suspend this outbreak earlier and faster. 
Table1 Characteristics of Patients with RSV infection During Outbreak on Hematology Ward

\begin{tabular}{|c|c|c|c|c|c|c|c|c|c|}
\hline Case & Sex & $\begin{array}{l}\text { Age } \\
\text { Ranges }\end{array}$ & $\begin{array}{l}\text { Underlying } \\
\text { Disease }\end{array}$ & Transplantation & co-infections & $\begin{array}{l}\text { Respiratory } \\
\text { disease }\end{array}$ & $\begin{array}{l}\text { RSV } \\
\text { Treatment }\end{array}$ & $\begin{array}{l}\text { viral } \\
\text { shedding }\end{array}$ & $\begin{array}{l}\text { RSV } \\
\text { outcome }\end{array}$ \\
\hline 1 & M & $20-29$ & $\begin{array}{l}\text { Acute myeloid } \\
\text { leukemia }\end{array}$ & Allogeneic & / & / & $\mathrm{N}$ & 14 & Recovered \\
\hline 2 & M & $50-59$ & $\begin{array}{l}\text { Acute lymphoid } \\
\text { leukemia }\end{array}$ & / & $\begin{array}{l}\mathrm{ESBL-KPN}(\mathrm{BC}) \\
\mathrm{EBV} \llbracket \mathrm{B} \rrbracket\end{array}$ & LRTID & $\mathrm{N}$ & $\begin{array}{l}{ }_{7}^{a} \text { At least } \\
\end{array}$ & Recovered \\
\hline 3 & M & $20-29$ & $\begin{array}{l}\text { Acute myeloid } \\
\text { leukemia }\end{array}$ & / & / & / & $\mathrm{N}$ & 7 & Recovered \\
\hline 4 & M & $30-39$ & $\begin{array}{l}\text { Acute lymphoid } \\
\text { leukemia }\end{array}$ & Allogeneic & E.faecalis,ABA(urine);MDRKP(s) & pneumonia & Y & 21 & Recovered \\
\hline 5 & M & $50-59$ & $\begin{array}{l}\text { Myelodysplastic } \\
\text { Syndromes }\end{array}$ & Allogeneic & / & $\begin{array}{l}\text { invasive } \\
\text { pulmonary } \\
\text { mycosis }\end{array}$ & Y & $\begin{array}{l}\text { at least } \\
7\end{array}$ & Recovered \\
\hline 6 & $\mathrm{~F}$ & $20-29$ & $\begin{array}{l}\text { Acute lymphoid } \\
\text { leukemia }\end{array}$ & Allogeneic & CMV & URTID & $\mathrm{Y}$ & $\begin{array}{l}\text { at least } \\
13\end{array}$ & Recovered \\
\hline 7 & $\mathrm{~F}$ & $40-49$ & Aplastic anemia & Allogeneic & CMV & LRTID & $\mathrm{N}$ & $\begin{array}{l}\text { at least } \\
14\end{array}$ & Recovered \\
\hline 8 & $\mathrm{~F}$ & $60-69$ & $\begin{array}{l}\text { Acute myeloid } \\
\text { leukemia }\end{array}$ & l & $\begin{array}{l}\text { stenotrophomonas } \\
\text { maltophilia } \llbracket \mathrm{S} \rrbracket\end{array}$ & $\begin{array}{l}\text { invasive } \\
\text { pulmonary } \\
\text { mycosis }\end{array}$ & Y & at least 6 & Recovered \\
\hline 9 & M & $20-29$ & $\begin{array}{l}\text { Acute myeloid } \\
\text { leukemia }\end{array}$ & Allogeneic & CMV;MDRKP(urine) & LRTID & $\mathrm{N}$ & 13 & Recovered \\
\hline 10 & M & $60-69$ & $\begin{array}{l}\text { Diffuse large B- } \\
\text { cell lymphoma }\end{array}$ & Autologous & / & pneumonia & $\mathrm{N}$ & at least 6 & Recovered \\
\hline 11 & M & $30-39$ & $\begin{array}{l}\text { Acute myeloid } \\
\text { leukemia }\end{array}$ & / & / & LRTID & $\mathrm{N}$ & 7 & Recovered \\
\hline 12 & M & $30-39$ & $\begin{array}{l}\text { Acute lymphoid } \\
\text { leukemia }\end{array}$ & Allogeneic & $\begin{array}{l}\text { CMV;stenotrophomonas } \\
\text { maltophilia } \mathbb{B C} \rrbracket\end{array}$ & pneumonia & $\mathrm{N}$ & 34 & Recovered \\
\hline 13 & $\mathrm{~F}$ & $40-49$ & $\begin{array}{l}\text { Acute myeloid } \\
\text { leukemia }\end{array}$ & / & / & pneumonia & $\mathrm{N}$ & $\begin{array}{l}\text { at least } \\
14\end{array}$ & Recovered \\
\hline 14 & $\mathrm{~F}$ & $30-39$ & $\begin{array}{l}\text { Myelodysplastic } \\
\text { Syndromes }\end{array}$ & Allogeneic & CRE(FC) & / & Y & $\begin{array}{l}\text { at least } \\
34\end{array}$ & Recovered \\
\hline 15 & $\mathrm{~F}$ & $30-39$ & $\begin{array}{l}\text { Hodgkin } \\
\text { lymphoma }\end{array}$ & Autologous & I & pneumonia & $\mathrm{Y}$ & 27 & Recovered \\
\hline 16 & $M$ & $50-59$ & $\begin{array}{l}\text { Acute myeloid } \\
\text { leukemia }\end{array}$ & / & l & pneumonia & $\mathrm{N}$ & 7 & Recovered \\
\hline 17 & M & $70-79$ & $\begin{array}{l}\text { Multiple } \\
\text { myeloma }\end{array}$ & / & / & LRTID & $\mathrm{N}$ & at least 3 & Recovered \\
\hline 18 & M & $70-79$ & $\begin{array}{l}\text { Acute myeloid } \\
\text { leukemia }\end{array}$ & l & I & l & $\mathrm{N}$ & 7 & Recovered \\
\hline 19 & M & $30-39$ & $\begin{array}{l}\text { Acute myeloid } \\
\text { leukemia }\end{array}$ & Allogeneic & CMV $\triangle \mathrm{CDI} \triangle \mathrm{F} \otimes$ & $\begin{array}{l}\text { invasive } \\
\text { pulmonary } \\
\text { mycosis }\end{array}$ & $\mathrm{Y}$ & 33 & Recovered \\
\hline 20 & $\mathrm{~F}$ & $50-59$ & $\begin{array}{l}\text { Myelodysplastic } \\
\text { Syndromes }\end{array}$ & Allogeneic & CMV & pneumonia & $\mathrm{Y}$ & 7 & Recovered \\
\hline 21 & $\mathrm{~F}$ & $40-49$ & $\begin{array}{l}\text { Acute } \\
\text { promyelocytic } \\
\text { leukemia }\end{array}$ & l & UTI & URTID & $\mathrm{N}$ & at least 3 & Recovered \\
\hline 22 & $\mathrm{~F}$ & $70-79$ & $\begin{array}{l}\text { Acute } \\
\text { promyelocytic } \\
\text { leukemia }\end{array}$ & / & / & pneumonia & $\mathrm{N}$ & at least 8 & Recovered \\
\hline 23 & $M$ & $60-69$ & $\begin{array}{l}\text { Myelodysplastic } \\
\text { Syndromes }\end{array}$ & Allogeneic & / & pneumonia & $\mathrm{Y}$ & $\begin{array}{l}\text { at least } \\
16\end{array}$ & Recovered \\
\hline 24 & $\mathrm{~F}$ & $70-79$ & Aplastic anemia & / & E.coli(urine) & / & $\mathrm{N}$ & 12 & Recovered \\
\hline
\end{tabular}


Abbreviations: B,blood; BC,blood culture; F,faeces; FC,fecal culture; S,sputum; RSV treatment refers to ribavirin or IVIG; a, patients cannot be monitored for RSV persistence after discharge, some patients can only be monitored for relatively persistent RSV infection.

\section{Discussion}

In total, 24 patients shown in Fig 1 were all RSV positive and there were no fatal cases. This is consistent with some studies where RSV positivity in immunocompromised patients was not associated with any fatal outcomes ${ }^{[13-14]}$.

Except case 23 had been admitted in the ward for a while, all had some respiratory disease or symptoms except case14,24,(seen in Table 1).Case 1,3,18 were asymptomatic.Prior to the outbreak, case 14,15(Table 1)had just completed bone marrow transplants,case 23 also had just completed in the BMT Unit.They were transferred back to the Hematology Unit after the transplantation. The first case 24 were tested positive for RSV on June 24th,2020,which was nosocomial acquired,and then case 14,15,23 were tested positive 6 days later,case 14 was also a hospital acquired RSV case,but case 15,23 had a relative with respiratory disease and may not be true nosocomial acquired RSV infection cases.Along with bed occupancy and redeployment, both direct and indirect patient to patient transmission was possible before samples were tested RSV positive,this is also in line with the previous studies ${ }^{[7,15]}$. However,it was also possible that transmission by HCWs or infected visitor who may be the source. The frequency of patient-to patient contact by visiting each other may also be an important risk factor for cross infection among the inpatients.Taking all epidemiological data into account,random introduction of community-acquired RSV was the explanation of this outbreak.

Standard RSV infection control measures were largely consistent with previous recommendations for hematologic disorder patients ${ }^{[16-17]}$. The additional measures,strict isolation of infected patients, suspension of all social activities, personnel protective equipment for all HCWs in patient rooms,and surgical masks for all patients and visitors,should cut off all possible RSV transmission pathways during the outbreak.RSV was once temporarily detected on the ring bell of case 17 , this was described in previous study ${ }^{[18]}$, thus contact transmission through the hands of staff was conceivable for nosocomial acquisition.Obviously hand hygiene compliance and cough etiquette are critical for infection control.Besides,patient education on wearing mask and decreased unnecessary visits play another important role in interrupting transmission during this outbreak especially for the droplet and contact transmitted pathogen

Therefore,early in the outbreak,we focused on patient to patient transmission, isolation for infected patients had been a key measure in the infection control bundles.Infected patients were isolated for 8 days and re-sampled for RSV in order to interrupt infection chains.One infected patient(case 15)was re-tested positive on day 7 after the first negative test.This underlines the importance of repeated samples ${ }^{[7]}$.As all these measures required larger isolation capability in the ward,so we decided to restrict elective admissions.

We detected prolonged RSV shedding in this outbreak,which had been described in hematology patients ${ }^{[19]}$. To effectively control the outbreak, we took this finding seriously and repeated the test in these immunocompromised patients as we had done.Negative RSV results were taken to end the quarantine as reported $^{[20]}$.Actually,two pursuant negative results were necessary for case 15 (see Fig 1).

Personnel protective equipment(PPE)plays a vital role as an effective infection control measure to prevent RSV nosocomial transmission,because RSV can be transmitted via symptomless or asymptomatically infected individuals. The value of PPE for reducing nosocomial RSV transmission was also demonstrated by French et,al ${ }^{[21]}$.Studies have shown that infected staff especially in hematology ward can be involved in the outbreak,who should not participate in direct patient care activities.Staff screening is recommended and staff caring for RSV-positive and negative patients could be separated ${ }^{[22]}$.

Active RSV screening on admission and once weekly for all patients in the ward ensured rapid isolation for RSV-positive patients. This is an effective infection control measure to control the outbreak. The start and end of screening depends on regional or local RSV epidemiology and seasonal variation ${ }^{[23]}$ and clinical reality of infection control practices.

\section{Conclusions}

RSV poses a significant threat for human respiratory infections. However, Chinese hospitals generally do not pay enough attention to RSV even the other respiratory virus. Through this event, the following lessons were learned. We should be aware of RSV cases on a daily basis and enforce the necessary infection control measures. Universal screening, early diagnosis, isolation and treatment of RSV are useful to interrupt further transmission. Monitoring RSV viral persistence,especially patients with hematological disorder to prevent resurgence. Routine surveillance of RSV infection is necessary to prevent seasonal outbreak. Infection control bundles such as strict isolation,PPE application,prevalence and admission screening are particularly useful during the COVID-19 pandemic as the transmissibility of SARS-CoV-2 may be increased by RSV coinfection.

\section{Abbreviations}

RSV:Respiratory syncytial virus; RTI:Respiratory tract infection; URTI:Upper respiratory tract infection; LRTI: BMT:Bone Marrow Transplant;HSCT:hematopoietic stem cell transplantation; HKU-SZH:The University of Hong Kong-Shenzhen Hospital; DFA: direct fluorescent antibody; HFC:high frequency contact. 


\section{Declarations}

\section{Ethics approval and consent to participate}

We obtained ethical approval for this study from the ethics committee of the HKU-SZH,and got the consent from study participants,which can be reflected in the their medical record.

\section{Consent for publication}

All the patients in the article give their consent for information about themselves to be published in BMC Infectious Diseases, manuscript number is INFD-D-2100771, corresponding author is Liu Jieling.

All the patients in the article understand that the information will be published without their name attached, but that full anonymity cannot be guaranteed.

All the patients in the article understand that the text and any pictures or videos published in the article will be freely available on the internet and may be seen by the general public. The pictures, videos and text may also appear on other websites or in print, may be translated into other languages or used for commercial purposes.

All the patients in the article have been offered the opportunity to read the manuscript.

\section{Availability of data and material}

All data generated or analysed during this study are included in this published article.Table 1,figure 1,figure 2 and figure 3 all support our findings.

\section{Competing interests}

The authors declare that they have no competing interests.

\section{Funding}

We received funding from the Sanming Project of Medicine in Shenzhen,China

\section{Authors' contributions}

\section{Yanjie Xia*, Huarui Xiao, Jin Yang, Qiaoling Tian,Fanfan Xing,Lingling Xie,Xue Wang,Jieling Liu\#}

$\mathrm{Y} X$ conceived, carried out the study,conceived the study and wrote the manuscript. $\mathrm{J} L$ supervised the study and critically reviewed the manuscript. $\mathrm{HX}$ and $\mathrm{J}$ $\mathrm{Y}$ carried out the assay development. F X conceived the study. Q T,L X and X W took samples for medical staffs and patients, did data collection and analysis. All authors have read and approved the manuscript.

\section{Acknowledgements}

We thank Professor Yuen Kwok-Yung for critical reading and guidance of the manuscript.Also we thank the nurses and physicians working at the Department of Hematology and Bone Marrow Transplant Unit at the University of Hong Kong-Shenzhen Hospital for their commitment in containing this outbreak of RSV infections.

\section{Authors'Information}

*The first author,Yanjie Xia, Department of Clinical Microbiology and Infection Control(J Liu,Y Xia, H Xiao,J Yang,Q Tian, F Xing, X Wang), The University of Hong Kong-Shenzhen Hospital,Shenzhen,Guangdong Province,China

\#Corresponding auhtor,Jieling Liu, Department of Clinical Microbiology and Infection Control,The University of Hong Kong-Shenzhen Hospital,Shenzhen,Guangdong Province,China

Other suthors,Huarui Xiao, Jin Yang, Qiaoling Tian,Fanfan Xing,Lingling Xie,Xue Wang,Department of Clinical Microbiology and Infection Control,The University of Hong Kong-Shenzhen Hospital,Shenzhen,Guangdong Province,China

\section{References}

1. AT, Chang C, Gershwin ME, Gershwin LJ. Respiratory syncytial virus - A comprehensive review. Clin Rev Allergy Immunol. 2013;45:331-79.

2. Bont L, Checchia PA, Fauroux B, Figueras-Aloy J, Manzoni P, Paes B, et al. Defining the Epidemiology and Burden of Severe Respiratory Syncytial Virus Infection Among Infants and Children in Western Countries. Infect Dis Ther. 2016;5:271-98.

3.Hall CB,Long CE,Schnabel KC. Respiratory syncytial virus infections in previously healthy working adults.Clin Infect Dis 2001;33:792-796. 
4.Couch RB,Englund JA,Whimbey E.Respiratory viral infections in immunocompetent and immunocompromised persons. Am J Med,1997;102:2-9 discussion $25-6$.

5. Khanna N, Widmer AF, Decker M, Steffen I, Halter J, Heim D, et al.Respiratory Syncytial Virus Infection in Patients with Hematological Diseases:Single-Center Study and Review of the Literature. Clin Infect Dis. 2008;46:402-12.

6. Avetisyan G, Mattsson J, Sparrelid E, Ljungman P. Respiratory syncytial virus

infection in recipients of allogeneic stem-cell transplantation: a retrospective

study of the incidence, clinical features, and outcome. Transplantation. 2009;

88:1222-6.

7.Lehners N, Schnitzler P, Geis S, Puthenparambil J, Benz MA, Alber B, et al. Risk factors and containment of respiratory syncytial virus outbreak in a hematology and transplant unit. Bone Marrow Transplant. 2013;48:1548-53.

8.Kelly SG, Metzger K, Bolon MK, Silkaitis C, Mielnicki M, Cullen J, et al. Respiratory syncytial virus outbreak on an adult stem cell transplant unit. Am J Infect Control. 2016;44:1022-6.

9.Inkster T, Ferguson K, Edwardson A, Gunson R, Soutar R. Consecutive yearly

outbreaks of respiratory syncytial virus in a haemato-oncology ward and efficacy of infection control measures. J Hosp Infect. 2017;96:353-9.

10.Hirsch HH, Martino R, Ward KN, Boeckh M, Einsele H, Ljungman P. Fourth European conference on infections in leukaemia (ECIL-4): Guidelines for diagnosis and treatment of human respiratory syncytial virus, parainfluenza virus, metapneumovirus, rhinovirus, and coronavirus. Clin Infect Dis. 2013;56: 258-66.

11.Waghmare A, Englund JA, Boeckh M. How I treat respiratory viral infections in the setting of intensive chemotherapy or hematopoietic cell transplantation. Blood. 2016;127:1-3.

12.Shah Jharna N,Chemaly Roy F. Management of RSV infections in adult recipients of hematopoietic stem cell transplantation.[J]. Blood,2011,117:2755-63.

13. Aslan T,Fassas A B,Desikan R,Siegel D,Munshi N,Mehta J,Singhal S,Barlogie B,Anaissie E. Patients with multiple myeloma may safely undergo autologous transplantation despite ongoing RSV infection and no ribavirin therapy.[J]. Bone marrow transplantation,1999,24:505-9.

14.Anaissie Elias J,Mahfouz Tahsine H,Aslan Turan,Pouli Anastasia,Desikan Rahman,Fassas Athanasios,Barlogie Bart. The natural history of respiratory syncytial virus infection in cancer and transplant patients: implications for management.[J]. Blood,2004,103:1611-17.

15.Jensen Tomas Ostergaard,Stelzer-Braid Sacha,Willenborg Christiana,Cheung Carol,Andresen David,Rawlinson William,Clezy Kate. Outbreak of respiratory syncytial virus (RSV) infection in immunocompromised adults on a hematology ward.[J]. Journal of medical virology,2016,88:1827-31.

16.Hirsch HH,Martino R,Ward KN,Boeckh M,Einsele H,Ljungman P. Fourth European Conference on Infections in Leukaemia (ECIL-4): guidelines for diagnosis and treatment of human respiratory syncytial virus, parainfluenza virus, metapneumovirus, rhinovirus, and coronavirus. Clin Infect Dis 2013;56:258-266.

17.Tomblyn M,Chiller T,Einsele H,Gress R,Sepkowitz K,Storek J,Wingard J R,Young J-A H,Boeckh M J. Guidelines for preventing infectious complications among hematopoietic cell transplant recipients: a global perspective. Preface.[J]. Bone marrow transplantation, 2009,15:1143-238.

18.Kramer Axel,Schwebke Ingeborg,Kampf Günter.How long do nosocomial pathogens persist on inanimate surfaces?[J]. BMC infectious diseases,2006,6:130.

19.Lehners N,Tabatabai J,Prifert C,Wedde M,Puthenparambil J,Weissbrich B,et al. Long-term shedding of influenza virus, parainfluenza virus, respiratory syncytial virus and nosocomial epidemiology in patients with hematological disorders. PloS One,2016;11:1-17.

20.Von Lilienfeld-Toal M,Berger A,Christopeit M,Hentrich M,Heussel CP,et al.Community acquired respiratory virus infections in cancer patients-Guideline on diagnosis and management by the Infectious Diseases Working Party of the German Society for haematology and Medical Oncology.Eur $\mathrm{J}$ Cancer.2016;67:200-12.

21.French CE,Mckenzie BC,Coope C,Rajanaidu S,Paranthaman K,Pebody R,et al. Risk of nosocomial respiratory syncytial virus infection and effectiveness of control measures to prevent transmission events:A systematic review. Influenza Other Respi.Viruses. 2016;10:268-90.

22.Shachor-Meyouhas $\mathrm{Y}, \mathrm{Zaidman} \mathrm{I}, \mathrm{Kra}-\mathrm{Oz} \mathrm{Z}$,Arad-Cohen $\mathrm{N}, \mathrm{Kassis}$,I.Detection,control,and management of a respiratory syncytial virus outbreak in a pediatric hematology-oncology department.J Pediatric Hematology Oncology.2013;35:124-8.

23.Terletskaia-Ladwig E,Enders G,Schalasta G,Enders M.Defining the timing of respiratory syncytial virus(RSV) outbreaks:an epidemiological study:BMC Infect Dis.2005;5:20.

\section{Figures}




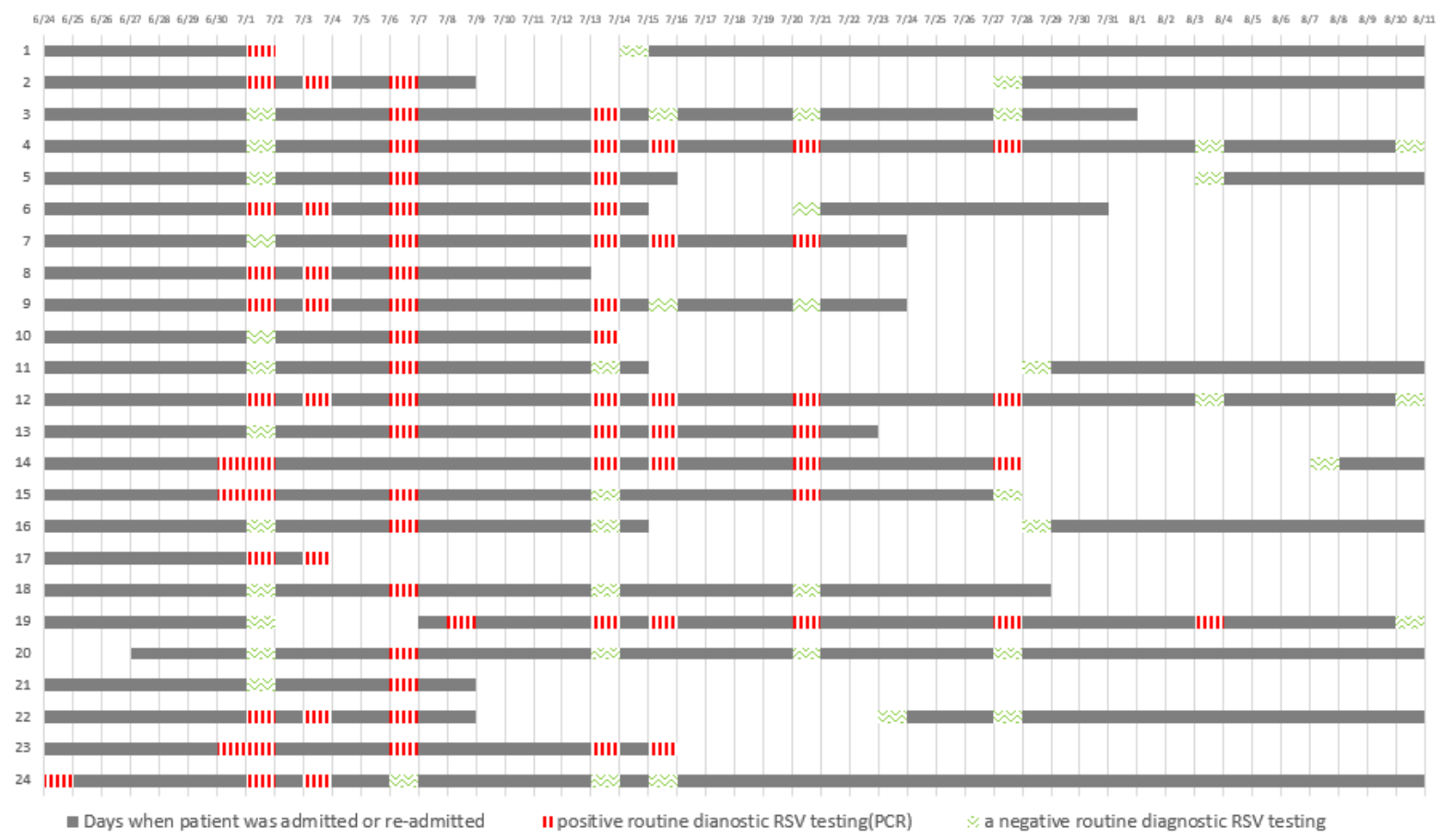

\section{Figure 1}

Outbreak timeline

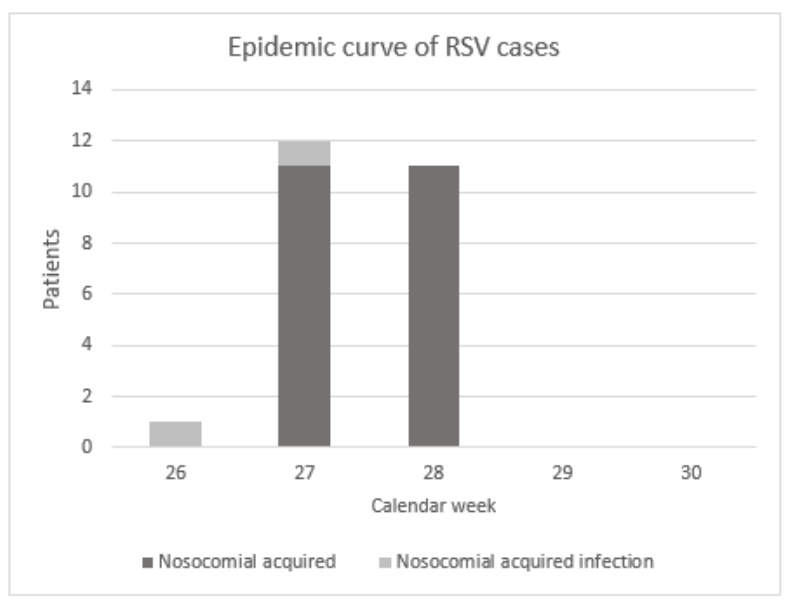

\section{Figure 2}

Epidemic curve of the RSV outbreak .(The number of newly diagnosed patients with RSV infection is given for the first three calendar weeks,no new patients were subsequently diagnosed.

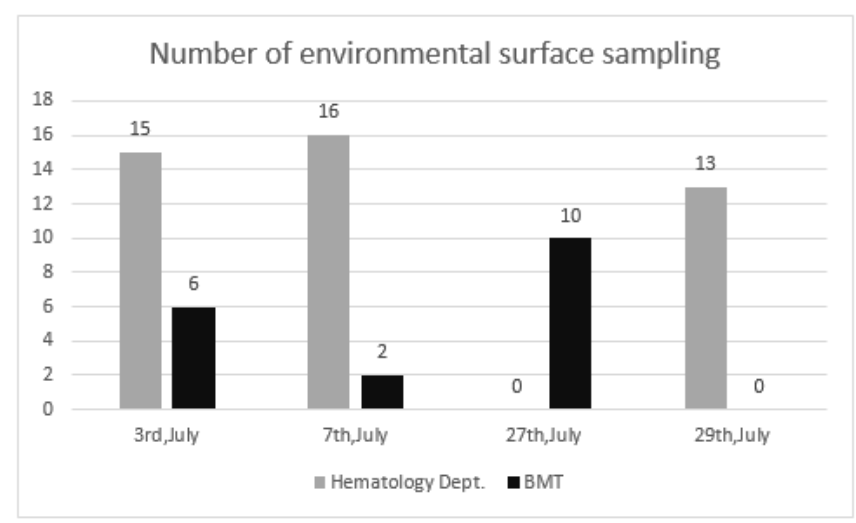


Figure 3

Number of environmental surface sampling on Hematology Ward and SCT Unit

Page $9 / 9$ 